\title{
PENGGUNAAN MEDIA INTERAKTIF BERBASIS WEB UNTUK MENINGKATKAN MOTIVASI DAN HASIL BELAJAR (Studi Kasus di Universitas Abdurrab Pekanbaru Riau)
}

\author{
USE OF WEB-BASED INTERACTIVE MEDIA \\ FOR INCREASE OF MOTIVATION AND LEARNING OUTCOMES \\ (Case Study at the University Abdurrab Pekanbaru Riau)
}

\author{
Kori Cahyono \\ Badan Penelitian dan Pengembangan Provinsi Riau \\ Jalan Diponegoro Nomor 24 A, Pekanbaru \\ E-mail: servernayaf7@yahoo.com \\ Diterima: 19 Oktober 2013; direvisi 28 Oktober 2013; disetjui: 18 November 2013
}

\begin{abstract}
Abstrak
Motivasi dan hasil belajar adalah dua faktor penting dalam menentukan efektivitas proses pembelajaran. Hasil belajar mata kuliah pemrograman berorientasi objek siswa rendah selama dua tahun terakhir. Hal ini mungkin disebabkan oleh bentuk materi yang masih abstrak sehingga motivasi belajar siswa rendah. Penelitian tindakan kelas bertujuan menggambarkan proses pembelajaran menggunakan media interaktif berbasis web untuk meningkatkan motivasi dan hasil belajar siswa. Obyek penelitian adalah siswa jurusan Teknik Informatika Abdurrab University. Penelitian dilakukan dalam dua siklus penelitian tindakan. Setiap siklus penelitian terdiri dari empat tahap yaitu perencanaan, tindakan, observasi dan refleksi. Untuk mengukur hasil penelitian menggunakan tiga instrumen yaitu kuesioner motivasi, lembar observasi, dan lembar evaluasi hasil belajar. Hasil analisis data menunjukkan bahwa ada peningkatan motivasi siswa sebesar $17,65 \%$, dan peningkatan hasil belajar sebesar $44,12 \%$.
\end{abstract}

Kata kunci: motivasi; hasil belajar; media interaktif berbasis web; penelitian tindakan

\begin{abstract}
Motivation and learning outcomes are two important factors in determining the effectiveness of the learning process. The results of student learning object-oriented programming is low during the last two years. This may be caused by a form of matter that remains abstract so that students' motivation is low. Classroom action research aims to describe the process of learning to use web-based interactive media to enhance student motivation and learning outcomes. Object of research is a student majoring in Computer Science Abdurrab University. The study was conducted in two cycles of action research. Each cycle consisted of four phases of planning, action, observation and reflection. To measure the results of the study used three instruments, namely the motivation questionnaires, observation sheets, and evaluation of learning outcomes sheet. The results of data analysis showed that there was an increase of $17.65 \%$ student motivation, and improved learning outcomes for $44.12 \%$.
\end{abstract}

Keywords: motivation; learning outcomes; web-based interactive media; action research

\section{PENDAHULUAN}

Ilmu pengetahuan dan teknologi (Iptek) di bidang pendidikan berkembang pesat dan menuntut perguruan tinggi sebagai lembaga pendidikan formal untuk dapat menghasilkan lulusan yang bermutu dan berkualitas. Menurut Undang-Undang Nomor 20 Tahun 2003 tentang Sistem Pendidikan Nasional, pendidikan adalah usaha sadar dan terencana untuk mewujudkan suasana belajar dan proses pembelajaran agar peserta didik secara aktif mengembangkan potensi dirinya untuk memiliki kekuatan spiritual keagamaan, pengendalian diri, kepribadian, kecerdasan, akhlak mulia, serta keterampilan yang diperlukan dirinya, masyarakat, bangsa dan negara.
Universitas Abdurrab Pekanbaru Riau (Univrab) sebagai institusi pendidikan berbasis Iptek selalu menghimbau para dosennya untuk melaksanakan dan mengoptimalkan proses belajar mengajar (PBM) pada semua mata kuliah, termasuk mata kuliah pemograman berorientasi obyek (object oriented programming/OOP).

Kompetensi yang diharapkan dari mata kuliah OOP di kurikulum teknik informatika Univrab adalah siswa dapat memahami konsep dan paradigma pemograman yang berorientasi pada pembuatan object-object (object oriented) secara terstruktur sehingga siswa mampu mengimplementasikan konsep tersebut ke dalam bahasa pemograman java dan memberikan dasar pengetahuan kepada siswa untuk mengikuti sertifikasi bidang pemograman. 
Ilmu komputer dan matematika adalah ilmu yang banyak mengandung konsep dengan tingkat generalisasi tinggi dan bersifat abstrak. Menurut Mardiyono (2005), matematika sebagai ilmu dasar komputer merupakan obyek yang bersifat abstrak. Adanya sifat abstrak ini, siswa merasa sulit dalam memahami materi sehingga mengakibatkan berkurangnya motivasi belajar yang berpengaruh pada menurunnya hasil belajar sebagai wujud dari nilai-nilai dan kemampuan yang diperoleh siswa melalui proses pembelajaran.

Proses belajar mengajar mata kuliah OOP di laboratorium komputer Univrab adalah belajar dengan menggunakan buku teks yang penyajiannya belum terstruktur dan bersifat abstrak. Pengajar menulis ulang materi dari buku teks di whiteboard. Pengajar tidak menjelaskan konsep pemograman secara mendalam, tidak memberikan contoh kasus dan implementasi program komputer serta kurang memberikan tugas untuk diskusi kelompok. Metode ini kurang memotivasi siswa sehingga tidak efektif dalam memberikan hasil belajar secara optimal.

Penelitian ini memberikan pengembangan inovasi model dan strategi pembelajaran melalui pendekatan penggunaan media interaktif berbasis web untuk meningkatkan motivasi dan hasil belajar siswa. Yang menjadi rumusan masalah dalam penelitian ini antara lain: 1) Apakah penggunaan media interaktif berbasis web dapat meningkatkan motivasi belajar siswa? 2) Apakah penggunaan media interaktif berbasis web dapat meningkatkan hasil belajar siswa?

Tujuan penelitian adalah: 1) Menganalisis pembelajaran dengan menggunakan media interaktif berbasis web dapat meningkatkan motivasi belajar siswa; dan 2) Menganalisis pembelajaran dengan menggunakan media interaktif berbasis web dapat meningkatkan hasil belajar siswa.

Motivasi belajar memegang peranan sangat penting untuk mendorong timbulnya perbuatan belajar. Menurut Winkel (1996), motif belajar yaitu seluruh daya penggerak psikis dalam diri seseorang yang dapat menimbulkan aktivitas belajar dalam mencapai tujuan. Kesuksesan belajar sangat dipengaruhi oleh motif-motif yang ada pada siswa, dan motif itu timbul karena adanya kebutuhan. Kebutuhan belajar siswa akan timbul apabila mereka menyadari dan yakin bahwa materi yang disajikan sangat bermanfaat bagi dirinya.

Menurut Soekamto (1995), motivasi sebagai tenaga pendorong atau penggerak yang menyebabkan adanya tingkah laku, yaitu bila siswa mempunyai motivasi positif maka siswa akan:

a. Memperlihatkan minat, mempunyai perhatian;

b. Bekerja keras, serta memberikan waktu kepada usaha tersebut; dan

c. Terus bekerja keras sampai tugas terselesaikan.

Menurut Anderson dalam Sadiman (1991), pengajar/guru perlu memperhatikan daftar kelompok media instruksional, karakteristik dan kemampuan masing-masing media agar dapat memilih media mana yang sesuai dengan kondisi dan kebutuhan dalam pembelajaran. Penggunaan media instruksional dapat digabungkan agar pembelajaran berlangsung secara efektif dan efesien. Kelompok media dijelaskan dalam Tabel 1.

Tabel 1. Kelompok Media Instruksional.

\begin{tabular}{|c|c|c|}
\hline No & Kelompok Media & Media Instruksional \\
\hline 1 & Audio & $\begin{array}{l}\text { - } \quad \text { Pita audio (rol atau kaset) } \\
\text { - } \quad \text { Piringan audio } \\
\text { Radio (rekaman siaran) }\end{array}$ \\
\hline 2 & Cetak & $\begin{array}{l}\text { - Buku teks terprogram } \\
\text { - Buku pegangan/manual } \\
\text { - Buku tugas }\end{array}$ \\
\hline 3 & Audio cetak & $\begin{array}{l}\text { - Buku latihan dilengkapi } \\
\text { kaset } \\
\text { - Gambar/poster } \\
\text { (dilengkapi audio) }\end{array}$ \\
\hline 4 & $\begin{array}{l}\text { Proyek visual } \\
\text { diam }\end{array}$ & $\begin{array}{l}\text { - Film bingkai (slide) } \\
\text { - Film rangkai (berisi pesan } \\
\text { verbal) }\end{array}$ \\
\hline 5 & $\begin{array}{lr}\text { Proyek } & \text { visual } \\
\text { diam } & \text { dengan } \\
\text { audio } & \end{array}$ & $\begin{array}{l}\text { - Film bingkai (slide) suara } \\
\text { - Film rangkai suara }\end{array}$ \\
\hline 6 & Visual gerak & $\begin{array}{l}\text { - Film bisu dengan judul } \\
\text { (caption) }\end{array}$ \\
\hline 7 & $\begin{array}{l}\text { Visual gerak } \\
\text { dengan audio }\end{array}$ & $\begin{array}{l}\text { - Film suara } \\
\text { - Video/VCD/DVD }\end{array}$ \\
\hline 8 & Benda & $\begin{array}{l}\text { - Benda nyata } \\
\text { - Model tiruan }\end{array}$ \\
\hline 9 & Komputer & $\begin{array}{l}\text { - Media berbasis komputer } \\
\text { - CAI (Computer Assisted } \\
\text { - CMstructional) } \\
\text { CMI (Computer Managed } \\
\text { Instructional) }\end{array}$ \\
\hline
\end{tabular}

Menurut Heinich (1996), multimedia merupakan kombinasi dari dua atau lebih media yang menyatu dalam bentuk informasi atau program pembelajaran. Pembelajaran menggunakan media interaktif berbasis web dan elektronik learning ( $e$ learning) merupakan pembelajaran multimedia. Komunikasi dan interaksi dua arah akan berlangsung lebih efektif antara guru dan siswa. Guru menyampaikan materi pembelajaran dan siswa memberikan tanggapan (response) terhadap materi pembelajaran yang diterimanya. Menurut Gagne (1988), guru tidak hanya berperan sebagai penyampai materi, tetapi juga menerima umpan balik (feedback) dari siswa dan memberikan pengukuhan (reinforcement) terhadap hasil belajar yang telah mereka tempuh.

Menurut Edgar Dale (1969), penggunaan media sangat penting dalam pendidikan untuk memperoleh hasil yang lebih optimal sesuai dengan tujuan yang diharapkan. 


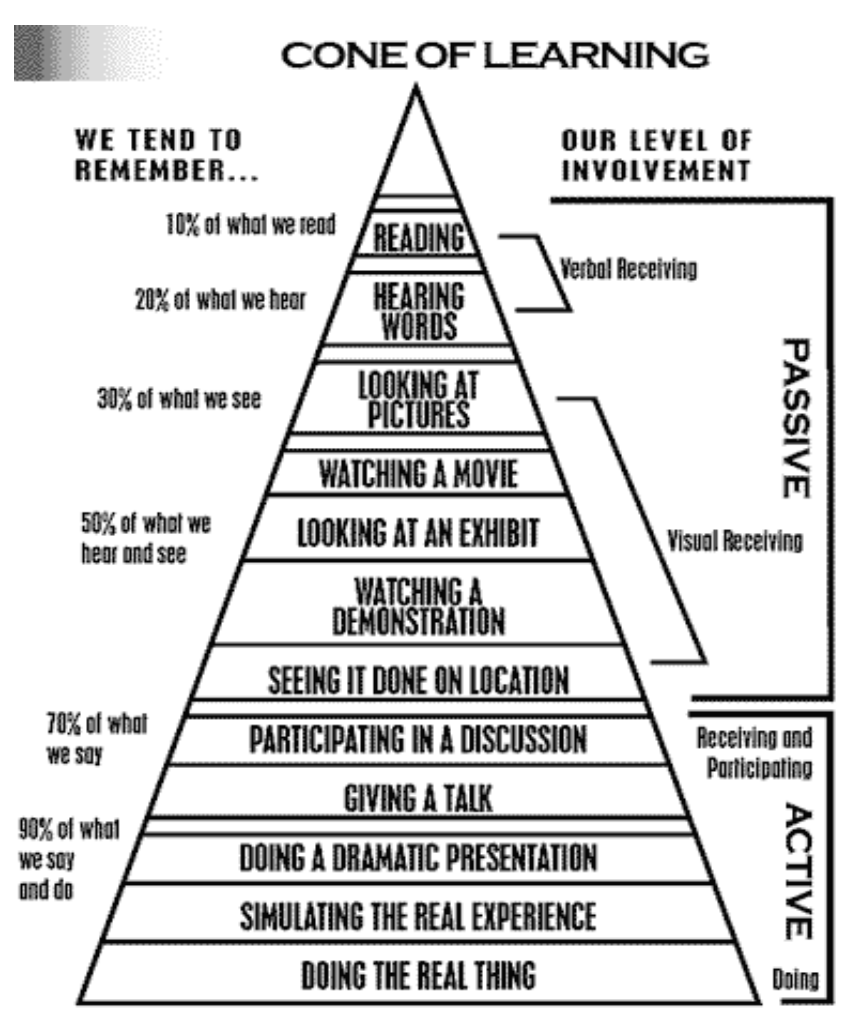

Gambar 1. Kerucut Pembelajaran Dale

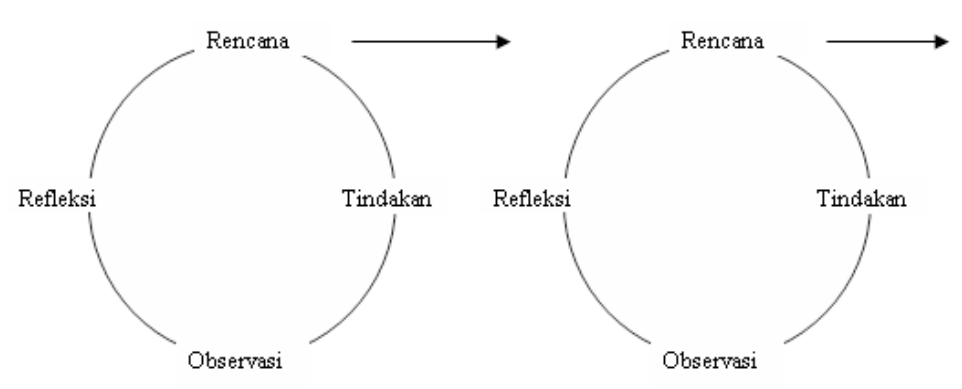

Gambar 2. Model Penelitian

\section{METODE PENELITIAN}

Penelitian ini menggunakan jenis penelitian tindakan kelas (classroom action research). Menurut Kemmis (1988), penelitian tindakan kelas adalah penelitian praktis yang dimaksudkan untuk memperbaiki pembelajaran di kelas. Model penelitian yang digunakan adalah seperti gambar 2 .

Model penelitian terdiri dari empat komponen yaitu perencanaan (planning), tindakan (action), pengamatan (observation) dan refleksi (reflection). Keempat komponen tersebut membentuk satu siklus penelitian.

Penelitian dilakukan di laboratorium komputer Univrab Pekanbaru Riau. Penelitian dilaksanakan selama 2 (dua) siklus penelitian tindakan kelas dalam waktu 3 bulan.
Populasi penelitian adalah siswa semester 4 (empat) Program Studi Teknik Informatika Tahun Ajaran 2011/2012 berjumlah 66 orang terdiri dari 51 laki-laki dan 15 wanita pada 2 (dua) kelas. Cara pengambilan sampel menggunakan metode Slovin.

$n=\frac{N}{1 .+N e^{2}}$

$n==\frac{66}{1+66 .(0.12)^{2}} \quad 34$

Dimana:

$\mathrm{n}$ adalah ukuran sampel, $\mathrm{N}$ adalah ukuran populasi, $e$ adalah tingkat kesalahan yang masih dapat ditolerir $(12 \%)$. Untuk menentukan responden menggunakan random sampling.

Jenis data dalam penelitian ini adalah data primer dan data sekunder. Data primer dengan menggunakan angket motivasi siswa, lembar 
pengamatan/observasi terhadap aktivitas siswa, dan lembar evaluasi hasil belajar. Data sekunder melalui literature sistem akademik Univrab dan buku-buku terkait.

\section{Angket motivasi belajar}

Angket motivasi disusun berdasarkan Keller's ARCS model (1987) dan dijabarkan menjadi 6 (enam) indikator seperti tabel 2 sebagai berikut.

Tabel 2. Indikator Motivasi.

\begin{tabular}{ll}
\hline \multicolumn{1}{c}{ Indikator Motivasi } & \multicolumn{1}{c}{ Sub Indikator } \\
\hline $\begin{array}{l}\text { Perhatian } \\
\text { (attention) }\end{array}$ & $\begin{array}{l}\text { Minat, aktif bertanya, } \\
\text { menanggapi, presentasi, } \\
\text { menjawab, bekerjasama }\end{array}$ \\
$\begin{array}{l}\text { Relevansi } \\
\text { (relevance) }\end{array}$ & $\begin{array}{l}\text { disiplin, serius } \\
\text { Harapan } \\
\text { (confidence) }\end{array}$ \\
$\begin{array}{l}\text { Kepuasan } \\
\text { Katisfaction) }\end{array}$ & $\begin{array}{l}\text { Rasa senang, berusaha } \\
\text { percaya diri }\end{array}$ \\
Tekun & $\begin{array}{l}\text { Kemampuan menyelesaikan } \\
\text { tugas dan soal latihan, } \\
\text { mencatat penjelasan }\end{array}$ \\
Rlet & $\begin{array}{l}\text { Rajin, tidak putus asa } \\
\text { menyelesaikan masalah } \\
\text { pemograman }\end{array}$ \\
\hline
\end{tabular}

Pernyataan-pernyataan angket motivasi dikategorikan menjadi dua bagian yang bersifat positif dan negatif terhadap materi. Angket ini disusun berdasarkan skala Likert dengan empat kategori jawaban yaitu, selalu (SL) bernilai 4, sering (SR) bernilai 3, jarang (JR) bernilai 2 dan tidak pernah (TP) bernilai 1 .

\section{Lembar Pengamatan}

Lembar pengamatan digunakan untuk mengukur aktivitas atau kegiatan siswa selama proses belajar.

\section{Evaluasi Hasil Belajar}

Instrumen ini digunakan untuk menilai kualitas hasil belajar siswa setiap akhir siklus.

\section{Media interaktif berbasis web}

Peneliti menggunakan media pembelajaran berbasis web seperti pada Lampiran Gambar 3. Proses interaksi menggunakan media web ditunjukkan pada Lampiran Gambar 4. Media ini di instalasi pada komputer belajar seperti pada Lampiran Gambar 5.

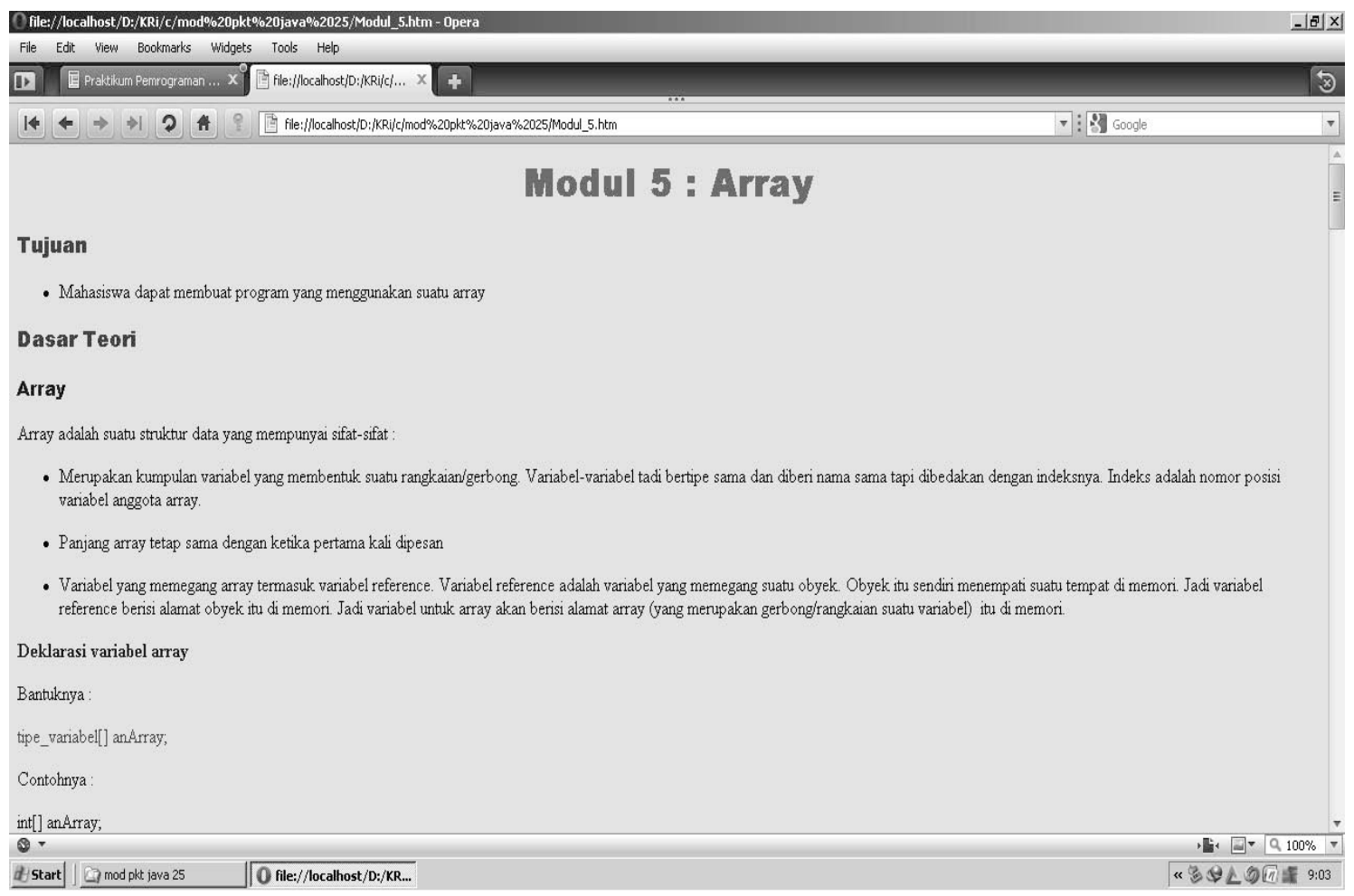

Gambar 3. Media Pembelajaran Berbasis Web. 


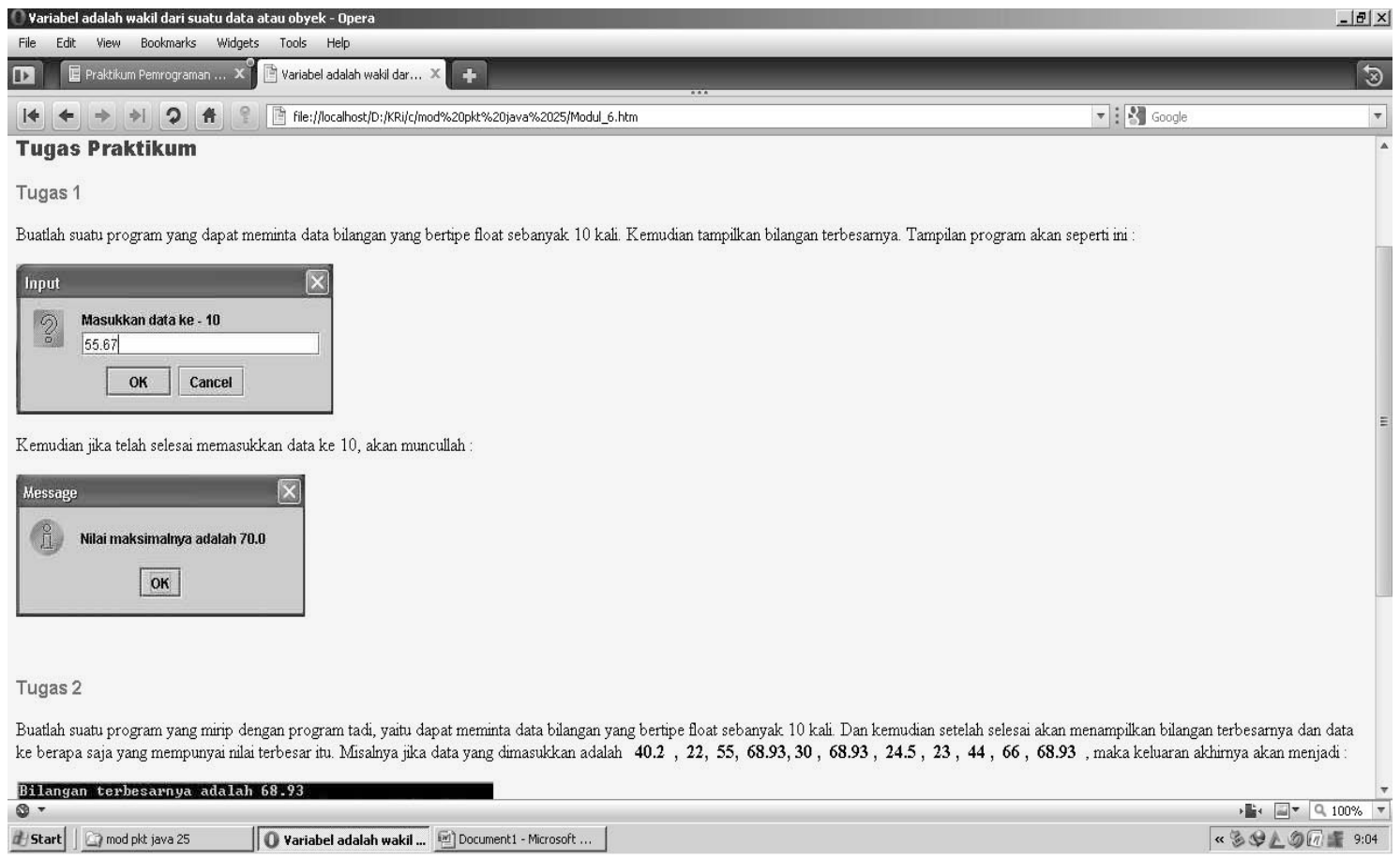

Gambar 4. Interaksi Pada Media Pembelajaran Berbasis Web

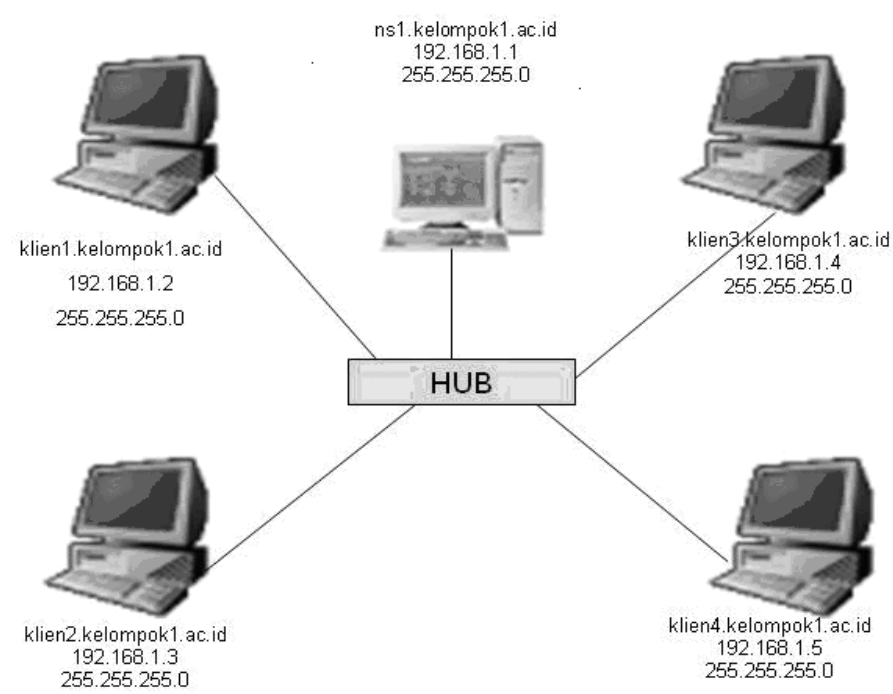

Gambar 5. Instalasi Media Pembelajaran pada Komputer

\section{Analisis Data}

Analisis data menggunakan analisis secara statistik terhadap hasil angket, hasil observasi dan hasil evaluasi. Analisis ini bertujuan untuk melakukan tindakan perbaikan yang dilakukan pada siklus penelitian selanjutnya. Uji validitas instrumen media web interaktif dan angket motivasi menggunakan analisis korelasi dengan membandingkan setiap pernyataan angket dengan nilai r-tabel $(\mathrm{N}=32 ; 5 \%)$ atau 0,349 dan r-tabel $(\mathrm{N}=24 ; 5 \%)$ atau 0,361 . Uji realibilitas instrumen penelitian menggunakan nilai Alpha Cronbach.
Peningkatan motivasi siswa diketahui dari uji-t terhadap hasil pengolahan angket motivasi menggunakan metode Nazir (2005) sebagai berikut: 


$$
\begin{aligned}
& B_{i}=y_{i}-x_{i} \\
& \bar{B}=\frac{\sum B_{i}}{n} \\
& V_{x}=\frac{n \sum B_{i}^{2}-\left(\sum B_{i}\right)^{2}}{n(n-1)} \\
& S_{d}=\sqrt{V_{x}} \\
& S_{B}=\frac{S_{d}}{\sqrt{n}} \\
& t=\frac{\bar{B}}{S_{B}}
\end{aligned}
$$

Dimana:

$\mathrm{B}_{\mathrm{i}}$ adalah difference, $\mathrm{B}$ adalah mean, $\mathrm{V}_{\mathrm{x}}$ adalah variance, $\mathrm{S}_{\mathrm{d}}$ adalah standard deviation, dan $\mathrm{S}_{\mathrm{B}}$ adalah standard error.

Rumusan hipotesis adalah:

$$
H_{0}: \mu_{B}=0 ; H_{A}: \mu_{B} \neq 0
$$

Jika ( $\mathrm{t}_{\text {hitung }} \geq \mathrm{t}_{\text {tabel }}$ ) maka hipotesis $H_{0}$ ditolak, dan sebaliknya hipotesis $H_{A}$ diterima.

Evaluasi hasil belajar dihitung menggunakan rumus sebagai berikut:

Hasil belajar $=(30 \%$ nilai tugas $)+(30 \%$ nilai soal latihan $)+(40 \%$ nilai kuis) .

Sedangkan kategori pemahaman siswa dibagi menjadi 3 (tiga) tingkatan yaitu kategori tinggi pada range $74<$ nilai $\leq 100$, kategori sedang pada range $50<$ nilai $\leq 74$, dan kategori rendah pada range nilai $\leq 50$.

\section{HASIL DAN PEMBAHASAN}

a. Analisa Uji Validitas, Reliabilitas dan Motivasi Siswa

Hasil uji validitas angket motivasi terdapat 6 (enam) butir pernyataan $(5,10,13,17,26$, dan 29) yang tidak valid karena nilainya berada di bawah $\mathrm{r}$ tabel $(0,349)$. Hasil uji validitas angket media web interaktif terdapat 3 (tiga) butir pernyataan $(3,12$, dan 19) yang tidak valid karena nilainya berada di bawah r-tabel $(0,361)$. Hasil uji reliabilitas angket motivasi menunjukkan nilai koefisien Alpha Cronbach sebesar 0,746 dan angket media web interaktif sebesar 0,744. Disimpulkan bahwa rangkaian soal dalam angket yang digunakan adalah reliabel. Analisa data motivasi menggunakan uji-t adalah:

Data diatas menunjukkan setiap indikator/variabel motivasi memiliki tingkat signifikansi jauh dibawah $\alpha=0,05$. Hal ini mengindikasikan keenam variabel signifikan secara statistik dimana $\mathrm{t}_{\text {hitung }} \geq \mathrm{t}_{\text {table }}(1,96)$. Kesimpulannya adalah penggunaan media interaktif berbasis web dapat meningkatkan motivasi belajar siswa.

\section{b. Hasil Penelitian Siklus 1 (satu)}

Hasil pengamatan kegiatan PBM ditunjukkan pada tabel 4 dan tabel 5 .

Keterangan:

P1 adalah kehadiran, P2 adalah pengajukan pertanyaan, menanggapi dan menjawab, P3 adalah berusaha serius mempelajari materi, P4 adalah senang mengerjakan soal latihan dan tugas yang

\begin{tabular}{|c|c|c|c|c|c|c|c|c|c|c|}
\hline \multirow{4}{*}{ Pertemuan } & \multicolumn{10}{|c|}{ Siklus 1} \\
\hline & \multicolumn{10}{|c|}{ Frekuensi Kegiatan } \\
\hline & \multicolumn{5}{|c|}{ Positif } & \multicolumn{5}{|c|}{ Negatif } \\
\hline & 1 & 2 & 3 & 4 & 5 & 1 & 2 & 3 & 4 & 5 \\
\hline 1 & 30 & 3 & 15 & 11 & 9 & 11 & 26 & 12 & 15 & 10 \\
\hline 2 & 32 & 3 & 14 & 12 & 11 & 10 & 26 & 6 & 17 & 12 \\
\hline 3 & 29 & 4 & 15 & 16 & 10 & 12 & 24 & 7 & 14 & 11 \\
\hline 4 & 31 & 5 & 18 & 15 & 12 & 11 & 23 & 8 & 12 & 10 \\
\hline Jumlah & 122 & 15 & 62 & 54 & 42 & 44 & 99 & 33 & 58 & 43 \\
\hline Prosentase & 89.71 & 11.03 & 45.59 & 39.71 & 30.88 & 32.35 & 72.79 & 24.26 & 42.65 & 31.62 \\
\hline
\end{tabular}
diberikan, $\mathrm{P} 5$ adalah rajin dan mampu menyelesaikan soal latihan dan tugas pemograman, N1 adalah

Tabel 3. Perbandingan Skor Motivasi Siswa Sebelum dan Sesudah Tindakan.

\begin{tabular}{lrrl}
\hline Indikator Motivasi & t-hitung & Signifikansi & Keterangan \\
\hline Perhatian (attention) & 7,409 & 0,000 & Signifikan \\
Relevansi (relevance) & 3,499 & 0,001 & Signifikan \\
Harapan (confidence) & 5,317 & 0,000 & Signifikan \\
Kepuasan (Satisfaction) & 4,632 & 0,000 & Signifikan \\
Tekun & 3,878 & 0,004 & Signifikan \\
Ulet & 4,993 & 0,000 & Signifikan \\
\hline
\end{tabular}

Sumber: Hasil pengolahan data primer

Tabel 4. Frekuensi Kegiatan Siswa dalam PBM Siklus 1.

Sumber: Hasil pengolahan data primer 
terlambat hadir, N2 adalah tidak aktif bertanya jika ada masalah, N3 adalah minta izin keluar kelas dan mengerjakan yang lain saat PBM, N4 adalah tidak mencatat penjelasan dan tidak senang mengerjakan soal latihan, dan N5 adalah malas menyelesaikan soal latihan dan tugas pemograman.

Data tabel 4 menunjukkan bahwa kegiatan positif siswa dengan jumlah kehadiran kuliah (P1) sebesar $89,71 \%$ artinya relevansi antara materi pembelajaran dan kondisi siswa dalam belajar tinggi. Siswa mengajukan pertanyaan, menanggapi dan menjawab (P2) rata-rata setiap pertemuan 4 orang $(11,03 \%)$ artinya perhatian siswa terhadap penjelasan materi rendah. Berusaha serius mempelajari materi (P3) berjumlah 16 orang $(45,59 \%)$ berarti harapan siswa berhasil cukup. Siswa merasa senang mengerjakan soal latihan dan tugas yang diberikan (P4) berjumlah 14 orang $(39,71 \%)$ berarti kepuasan siswa dalam belajar kurang. Siswa rajin dan mampu menyelesaikan soal latihan dan tugas pemograman (P5) sebanyak 11 orang $(30,88 \%)$ artinya siswa belum ulet dan tekun dalam belajar.

Kegiatan negatif siswa pada saat PBM adalah terlambat menghadiri kuliah (N1) rata-rata 11 siswa $(32,35 \%)$ artinya beberapa siswa kurang disiplin dalam belajar. Siswa tidak aktif di kelas (N2) sebesar 25 siswa $(72,79 \%)$. Siswa minta ijin dan mengerjakan kegiatan lain saat PBM (N3) rata-rata 8 siswa $(24,26 \%)$ artinya siswa kurang percaya diri terhadap materi kuliah. Siswa tidak tekun mencatat penjelasan dan tidak senang mengerjakan soal latihan (N4) berjumlah 14 siswa $(42,65 \%)$. Siswa malas menyelesaikan soal latihan dan tugas pemograman (N5) sebesar 31,62\%.
Hasil Evaluasi Siklus 1 (satu)

Hasil evaluasi belajar pada siklus 1 ditunjukkan pada Tabel 5.

Tabel 5. Sebaran Siswa untuk Masing-Masing Kategori pada Siklus 1.

\begin{tabular}{cccc}
\hline Kategori & & \multicolumn{2}{c}{ Siswa } \\
\cline { 3 - 4 } Pemahaman & Range Nilai & Jumlah & Persentase \\
\hline Tinggi & $74<$ Nilai $\leq 100$ & 5 & 14.71 \\
Sedang & $50<$ Nilai $\leq 74$ & 14 & 41.18 \\
Rendah & Nilai $\leq 50$ & 15 & 44.12 \\
Total & & 34 & 100 \\
\hline
\end{tabular}

Sumber: Hasil pengolahan data primer

Data tabel 5 menunjukkan bahwa persentase siswa dengan kategori pemahaman tinggi sebesar $14,71 \%$, siswa dengan kategori sedang $41,18 \%$ dan siswa dengan kategori rendah 44,12\%.

\section{c. Hasil Penelitian Siklus 2 (dua)}

Hasil pengamatan pada siklus 2 terdapat pada tabel 6. Frekuensi kegiatan positif siswa yaitu kehadiran (P1) sebesar 97,06\% artinya relevansi antara materi pembelajaran dan kondisi siswa dalam belajar meningkat. Mengajukan pertanyaan atau pendapat $(\mathrm{P} 2)$ rata-rata setiap pertemuan sebanyak 13 siswa $(38,24 \%)$ artinya perhatian siswa meningkat dan berusaha meningkatkan prestasi. Memperhatikan penjelasan (P3) meningkat rata-rata 25 siswa $(72,79 \%)$ artinya harapan siswa untuk berhasil dalam memahami materi meningkat. Siswa merasa senang mengerjakan soal latihan dan tugas yang diberikan (P4) rata-rata 24 siswa $(70,59 \%)$ artinya ada peningkatan kepuasan siswa dalam belajar. Siswa rajin dan mampu menyelesaikan soal latihan dan

Tabel 6. Frekuensi Kegiatan Siswa pada Siklus 2.

\begin{tabular}{|c|c|c|c|c|c|c|c|c|c|c|}
\hline \multirow{4}{*}{ Pertemuan } & \multicolumn{10}{|c|}{ Siklus 2} \\
\hline & \multicolumn{10}{|c|}{ Frekwensi Kegiatan } \\
\hline & \multicolumn{5}{|c|}{ Positif } & \multicolumn{5}{|c|}{ Negatif } \\
\hline & 1 & 2 & 3 & 4 & 5 & 1 & 2 & 3 & 4 & 5 \\
\hline 5 & 32 & 10 & 23 & 21 & 17 & 5 & 14 & 5 & 8 & 6 \\
\hline 6 & 33 & 13 & 25 & 21 & 20 & 4 & 15 & 4 & 8 & 5 \\
\hline 7 & 34 & 12 & 24 & 26 & 26 & 5 & 12 & 2 & 7 & 5 \\
\hline 8 & 33 & 17 & 27 & 28 & 29 & 6 & 10 & 3 & 6 & 3 \\
\hline Jumlah & 132 & 52 & 99 & 96 & 92 & 20 & 51 & 14 & 29 & 19 \\
\hline Prosentase & 97.06 & 38.24 & 72.79 & 70.59 & 67.65 & 14.71 & 37.50 & 10.29 & 21.32 & 13.97 \\
\hline
\end{tabular}

Sumber: Hasil pengolahan data primer

Tabel 7. Sebaran Siswa Masing-Masing Kategori pada Siklus 2.

\begin{tabular}{ccccc}
\hline Kategori & & \multicolumn{2}{c}{ Siswa } \\
\cline { 3 - 5 } Pemahaman & Range Nilai & Jumlah & Persentase \\
\hline Tinggi & $74<$ Nilai $\leq 100$ & 8 & 23.53 \\
Sedang & $50<$ Nilai $\leq 74$ & 26 & 76.47 \\
Rendah & Nilai $\leq 50$ & 0 & 0.00 \\
Total & & 34 & 100 \\
\hline
\end{tabular}

Sumber: Hasil pengolahan data primer 
tugas pemograman $(\mathrm{P} 5)$ rata-rata 23 siswa $(67,65 \%)$ berarti keuletan dan ketekunan belajar siswa meningkat.

Frekuensi kegiatan negatif siswa yaitu keterlambatan hadir (N1) berkurang rata-rata setiap pertemuan 5 siswa $(14,71 \%)$ artinya siswa berusaha memperhatikan hadir kuliah tepat waktu. Siswa tidak aktif di kelas (N2) berkurang sebesar $37,5 \%$ berarti ada peningkatan perhatian siswa. Siswa minta ijin dan mengerjakan kegiatan lain saat PBM (N3) berkurang menjadi rata-rata 4 siswa $(10,29 \%)$. Siswa tidak tekun mencatat penjelasan dan tidak senang mengerjakan soal latihan $(\mathrm{N} 4)$ berkurang rata-rata sebesar 7 siswa $(21,32 \%)$ dan Siswa malas menyelesaikan soal latihan dan tugas pemograman (N5) berkurang sebesar 13,97\%.

\section{Hasil Evaluasi Siklus 2 (dua)}

Hasil evaluasi belajar pada siklus 2 (dua) ditunjukkan pada Tabel 7.

Prosentase siswa kategori pemahaman tinggi sebesar 8 siswa $(23,53 \%)$. Siswa dengan kategori pemahaman sedang meningkat menjadi 26 siswa $(76,47 \%)$. Perbandingan persentase kegiatan positif dan kegiatan negatif siswa pada kedua siklus ditunjukkan pada Gambar 6.

Pada gambar 6 menunjukkan bahwa terjadi peningkatan aktifitas positif siswa dan pada gambar
7 menunjukkan berkurangnya kegiatan negatif siswa pada siklus 1 dan 2 .

\section{SIMPULAN}

Setelah dilakukan penelitian tindakan kelas selama 2 (dua) siklus, maka dapat disimpulkan sebagai berikut: 1) Penggunaan media pembelajaran interaktif berbasis web dapat meningkatkan motivasi belajar siswa. Hal ini diketahui dari uji-t terhadap indikator/variabel motivasi. Setiap indikator motivasi memiliki tingkat signifikansi jauh dibawah $\alpha=0,05$. Hal ini mengindikasikan keenam variabel signifikan secara statistik, dimana $\mathrm{t}$ hitung $\geq \mathrm{t}$ table $(1,96)$. Meningkatnya motivasi belajar siswa juga dapat dibuktikan dengan meningkatnya persentase aktivitas/kegiatan positif siswa dan menurunnya aktivitas negatif siswa pada siklus penelitian; 2) Penggunaan media pembelajaran interaktif berbasis web dapat meningkatkan hasil belajar siswa. Hal ini dapat diketahui dari meningkatnya rata-rata nilai hasil evaluasi siswa pada setiap siklus penelitian dan berkurangnya jumlah siswa yang berkategori tingkat pemahaman rendah.

Berdasarkan simpulan diatas, disarankan dari hasil penelitian adalah: 1) Siswa sebagai generasi muda bangsa, disarankan untuk lebih rajin belajar dan berusaha meningkatkan prestasinya melalui

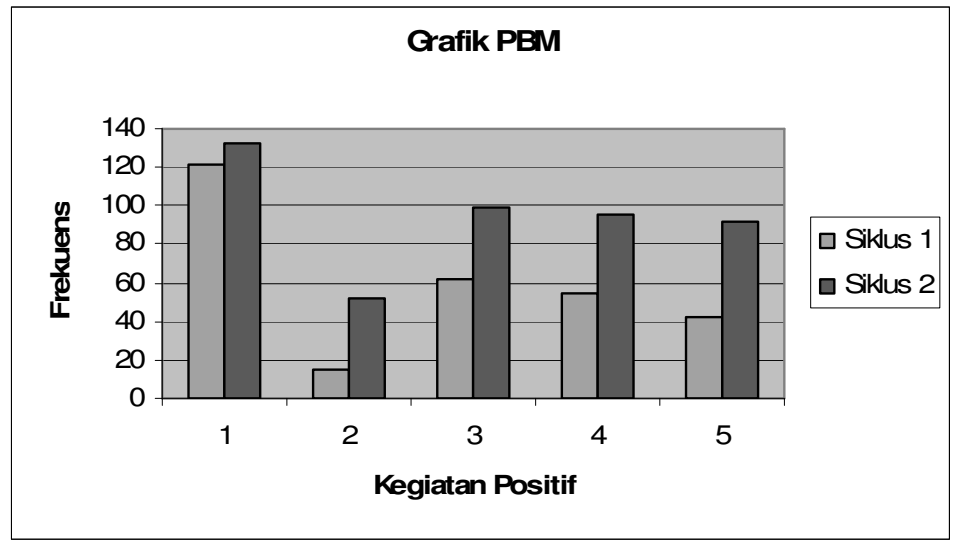

Gambar 6. Kegiatan Positif Siswa Selama Siklus 1 dan 2

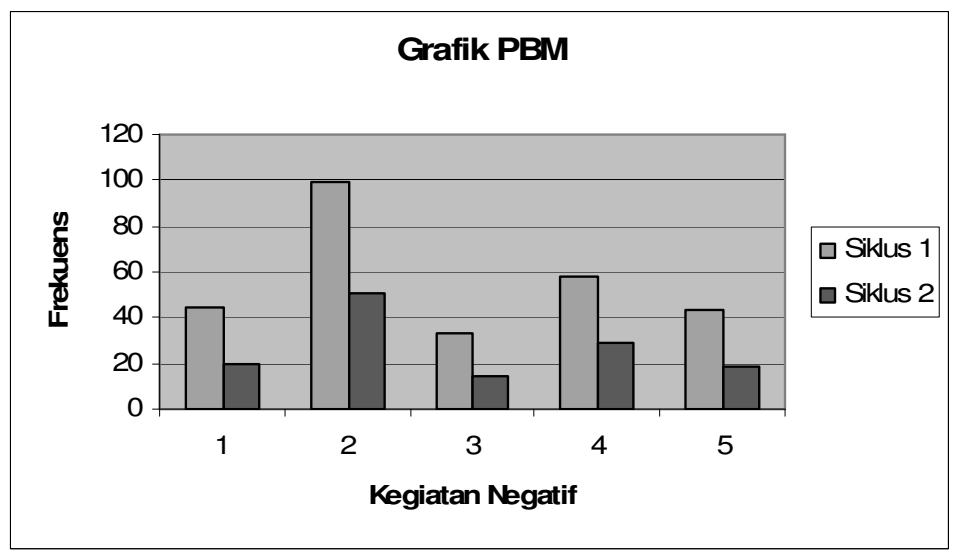

Gambar 7. Kegiatan Negatif Siswa Selama Siklus 1 dan 2 
pemanfaatan berbagai media pembelajaran; 2) Dosen dan Guru di bidang pendidikan untuk meningkatkan kualitas pembelajaran disarankan berinovasi dan mengembangkan media interaktif berbasis web. Materi pembelajaran berbasis web sebaiknya dibuat dalam bentuk visualisasi, beranimasi multimedia secara interaktif dan menarik agar lebih mudah dipahami oleh siswa sehingga PBM dapat berlangsung secara efektif dan efesien; dan 3) Program Studi Teknik Informatika Universitas Abdurrab Pekanbaru, untuk meningkatkan kualitas pembelajaran disarankan menginovasi dan mengembangkan media interaktif berbasis web dan e-learning untuk semua matakuliah agar PBM dapat berlangsung secara efektif dan efesien.

\section{DAFTAR PUSTAKA}

Arief S, Sadiman, dan A. Tresna Sastrawijaya. 1991. Pengembangan Program Pengajaran. Jakarta: PT. Rineka Cipta.

Cahyono, Kori. 2007. Penggunaan Media Interaktif Berbasis Web Untuk Meningkatkan Motivasi Dan Hasil Belajar Struktur Data Pemrograman Komputer Mahasiswa Kelas 2 Di Politeknik Caltex Riau. Tesis. Padang: Program Pascasarjana Universitas Negeri Padang.

Dale, E. 1969. Audio Visual Methos in Teaching. (Third Edition) New York: The Dryden Press.

Gagne, R.M. and M.P. Driscoll. 1988. Essentials of Learning for Instruction. New York: Prentice Hall, Inc.

Gagne, R.M. 1989. The Condition of Learning and Theory of Instruction. New York: Holt, Rinchart and Winston.

Heinich, et al . 1996. Instructional Media and Technology for Learning. New Jersey: Prentice Hall, Inc.

Keller, J. M. 1987. Development and Use of The ARCS Model of Motivational Design, Journal of Instructional Development, 10(3), 2-10. (http://www.arcsmodel.com/, diakses 29 Juni 2012).

Kemmis, Stephen and Mc Taggart, Robin. 1988. The Action Research Planner. Third Edition, Victoria: Deakin University Press.

Nazir, Moh. 2005. Metode Penelitian. Ciawi, Ghalia Indonesia

Soekamto dan Winataputra. 1995. Teori Belajar dan Model-Model Pembelajaran. Jakarta: Departemen Pendidikan dan Kebudayaan Republik Indonesia.

Sugeng, Mardiyono. 2005. Inovasi Pembelajaran Matematika dan Sistem Evaluasinya Berdasarkan
Kurikulum Berbasis Kompetensi, Makalah Disampaikan dalam Seminar Nasional Matematika dan Pendidikan Matematika. Departemen Pendidikan Nasional: Universitas Negeri Yogyakarta.

Undang-Undang Republik Indonesia Nomor 20 Tahun 2003 Tentang Sistem Pendidikan Nasional, Jakarta: Departemen Pendidikan Nasional Republik Indonesia.

Winkel, 1996. Psikologi Pengajaran. Edisi Revisi, Jakarta: PT Gramedia Widya Sarana. 